\title{
Two Politicians in a Realistic Experiment: Attraction, Discrepancy, Intensity of Delivery, and Attitude Change ${ }^{1}$
}

\author{
O. WIEGMAN ${ }^{2}$ \\ Technical University of Twente, The Netherlands
}

\begin{abstract}
The leader of the Socialists in the Dutch Parliament and his Liberal opponent participated in this realistic experiment. Identical TV interviews with the two politicians were recorded and shown to subjects of both parties. The intensity of delivery was also varied: emotional versus rational. Our findgins indicated that the experimental interveiw changed the attitude of the subjects. In addition, support was found for a second hypothesis: Attitude change was greater for the attractive source from the same party than for the less attractive source from the opposite party. Furthermore, our expectations were confirmed that attitude change would be greater with high than with low discrepancy. Although the intensity of delivery did have an effect on the credibility of the source-the emotional delivery scored lower-no effect on attitude change was found.
\end{abstract}

This study concerns the effect that political information presented on television has on the attitudes of the viewer. A significant feature of this experiment is that two well-known Dutch politicians participated: Mr. Van Thijn, who was the Socialist leader in the Dutch Parliament at the time, and his political opponent, Mr. Wiegel, leader of the Liberals in Parliament who later became Vice Premier. Completely identical experimental television interviews on a certain political topic were made with both political leaders, who at the request of the experimenter used exactly the same words and defended the exact same point of view. A video recording of these interviews was subsequently shown to members of the Socialist and Liberal parties and attitude change was measured.

Over the years there have been a number of scientific studies focusing on the effect of the mass media. This is not the place to examine all the theoretical work done on the subject. However, it is worth mentioning that many recent studies have shown that the mass media do have an effect, and that this is not restricted to reinforcing existing opinions and behavior (cf. Comstock,

\footnotetext{
${ }^{1}$ This article is part of an extensive study (Wiegman, de Roon, \& Snijders).

${ }^{2}$ Requests for reprints should be sent to Prof. Dr, O. Wiegman, Department of Psychology, Technical University of Twente, P.O. Box 217, 7500 AE Enschede, The Netherlands.
} 
1975, 1978; Foley, 1978, 1979; Liebert \& Schwartzberg, 1977; Wiegman, Baarda \& Seydel, 1983).

If the mass media do have an effect, the question arises as to whether this effect is direct or indirect. Watt and Van den Berg (1978) concluded from the reactions of the public to mass media reports concerning noise pollution that the mass media have a mainly direct effect. However, under certain conditions the effect may sometimes be more indirect than direct, as was demonstrated, for example, by Van den Ban (1964). Many factors in communication processes can be identified as restricting or reinforcing the effect of the media. One such factor is the issue of the message. Zucker (1978) was able to demonstrate that the direct influence of the mass media is greatest when the issue fulfills two criteria. First, the issue must not relate directly to the personal experience of the recipient. Second, the issue should not have had extensive news coverage. When the media have devoted a great deal of attention to an issue, there is a high probability that more or less fixed attitudes will have been formed, which are hard to change.

Taking Zucker's two criteria into account, our first hypothesis is that the political information presented by the two politicians will cause attitude change in the direction of the source.

As mentioned above, the subjects were confronted with either a Liberal politician or his Socialist counterpart, so that depending on party membership-Liberal or Socialist-the subject would be shown either a source from the subjects own party or a source from the opposing party.

It was assumed that in this way the credibility and the attraction of the source would be varied depending on the similarity or difference in party membership between the source and the subject. The source (the politician) has a high credibility and attraction if he or she belongs to the same party as the receiver and these are low if he or she belongs to the opposing party. We assume that the attraction of the source is related to his or her credibility. Like McGuire (1969) we consider credibility as having two aspects: expertise and objectivity. It has often been shown that an expert source is more effective than a less expert source (e.g., Aronson \& Golden, 1963; Hovland, Janis, \& Kelley, 1953). As regards the other aspects of credibility, namely the objectivity of the source, some studies have shown that a less objective source produces more opinion change (e.g., Watts \& Holt, 1979), but this has not been consistently confirmed (McGuire, 1969).

McGuire (1969) distinguishes three aspects relating to the attraction of the source: liking, similarity in attitudes and in group membership, and familiarity. Some research has already been done on the first two aspects. According to McGuire (1964), similarity leads to more attitude change; this was also found by Wiegman, de Roon, \& Snijders (1981). On the aspect of liking, McGuire assumes that a sympathetic source causes more attitude change than 
an unsympathetic source. However, in a few studies the opposite effect was shown (Himmelfarb \& Arazi, 1974; Jones \& Brehm, 1967).

In this experiment, in which politicians from opposing parties were presented, we assume that the variation between the two is related primarily to the attraction of the source, because there was not only a similarity or difference in group membership (political party) and in attitude (party ideology) but also a variation in liking. Of course, the difference in party membership of the source also has an effect on the credibility of the source. This certainly holds for objectivity but also to a lesser degree for expertise, since a top politician is always considered as having a certain expertise in his or her own field.

Thus, we primarily regard similarity in party membership between politician and subject as a variation in attraction. Consequently, our second hypothesis is: The attractive source from the same party will lead to more attitude change than the less attractive source from the opposing party.

A further step taken in this study was to vary the intensity of delivery. As regards the style of presentation, a good deal of research has been done on the dynamic versus the subdued presentation. Dietrich (1946) showed that a dynamic presentation of a radio message led to less attitude change than a presentation in a normal conversational tone. Vincenzo and Hendrick (1974), too, found that a dynamic presentation resulted in less attitude change. Furthermore, they determined that the dynamic source was perceived as less reliable than a subdued source. Pearce and Conklin (1971) varied the presentational style of four different topics. The messages were recorded and electronically filtered so that their content was incomprehensible. The researchers established that the message presented dynamically was seen as less reliable and less attractive. Bowers (1965) found that a dynamic presentation resulted in greater attitude change. Like Dietrich (1946), Bowers did not measure the credibility of the source, which makes the interpretation of his results difficult.

Coats and Schmidchens (1966) posited that, since a message presented in a dynamic way would be remembered more easily, it would lead to greater attitude change. However, they could find no evidence for this hypothesis in their study. Hovland, Lumsdaine, \& Sheffield (1949) also reported that no difference in attitude change and reliability of the source ensued from a dynamic or a subdued method of presentation.

On the whole, we may conclude that the evidence relating to the style of presentation presents a very inconsistent picture, particularly as far as attitude change is concerned. There is more agreement about the way in which presentational style affects the credibility and especially the reliability of the sources. To the extent that this attribute of the source was measured, we can say that a source with a dynamic presentation is always seen as less reliable than one with a subdued presentation.

In our study we compared a rational delivery with an emotional one. This 
variation corresponds with what has been described above as the dynamic versus the subdued presentation. In view of the inconsistent results derived from the relevant literature, we prefer not to propose a specific hypothesis about the effect of a rational versus an emotional delivery on attitude change. We opt instead for an exploratory approach.

The subjects were members of the Socialist party and the Liberal party, implying that there would initially be a difference between the two groups in attitude and hence discrepancy, independent of the TV interview. By discrepancy we mean the distance, measured on an attitude scale, between the opinion of the subject and that of the source. In some experiments a positive relation between discrepancy and attitude change was found, in that the amount of change apparently increased with increasing discrepancy (e.g., White, 1975), while in other studies a negative relationship was shown (e.g., Brock, 1967). According to Granberg and Campbell (1977), however, most studies indicate a curvilinear relation as there is a greater attitude change at an average level of discrepancy than at a high or low level of discrepancy. This accords with what has been predicted by several attitude theories (e.g., social judgment: Sherif, Sherif, \& Nebergall, 1965). Thus, if we are able to find differences in discrepancy between the Socialist and Liberal subjects on certain issues, we expect greater attitude change to take place at a high level of discrepancy than at a low level of discrepancy. Because of the political issue chosen in our experimental television interview we assume that opinions and attitudes had not yet been established and that the discrepancy that we call high is, relatively speaking, average.

\section{Method}

\section{Experimental Television Programs}

As we have said, the Socialist leader in Parliament, Mr. Van Thijn, and his political opponent, the Liberal leader, Mr. Wiegel, took part in the study. At the researcher's request, both politicians agreed to give an experimental television interview in which they would defend the same political standpoint in precisely the same words. The topic chosen was the establishment of a second national airport in the Markerwaard area. The practical reasons for this choice of topic were that neither the politicians nor their parties had in fact taken a stand on the issue, so that the opinions expressed in the experimental interviews would not be at variance with current political thinking and would not be discredited on those grounds.

Theoretically, the issue satistifed the following conditions. First, in a preliminary study it was found that the subjects had a very neutral opinion of the issue and that involvement was average, so that basically attitude change in both directions was possible (cf. Nemeth \& Endicott, 1976). Second, the topic 
met Zucker's two criteria (Zucker, 1978): The subjects had no direct personal experience of the topic because no such national airport existed and, as shown by our preliminary press analysis, the issue had rarely been in the news.

The experimental television interviews were produced by a professional team from the Dutch television company VARA. The programs were introduced by the chief editor of VARA's Behind the News and afterwards the well-known interviewer Joop Daalmeijer came on the screen and put eight questions to the politician concerned. The politicians answered the questions in the way that had been arranged beforehand. Both politicians advocated the establishment of a second national airport and stated that enlarging Amsterdam's airport was out of the qeustion, that none of the other regional airports was capable of enlargement, that the noise levels at Amsterdam's airport were further insupportable, that the choice of the Markerwaard area was best from an economic standpoint, that the decision should be taken as soon as possible, and that the Markerwaard option represented the least costly solution. Mr. Wiegel and Mr. Van Thijn were interviewed in both a rational manner and an emotional manner. All four interviews lasted about 15 minutes each. In the rational interview, the politician presented his opinion soberly with few gestures and little variety in intonation. In the emotional interview, the politician behaved as if he were strongly committed to the issue and wanted to impress his views upon the viewer. His style of speech was dynamic, with a good deal of gesticulation.

\section{Attitude Measurements}

We measured the attitude toward not only the main issue, namely the establishment of a second national airport, but also attitudes toward six related issues arising from the politicians's arguments, i.e., the Markerwaard as the appropriate location, the pressure for a quick decision, the increase in air traffic, the objection toward increasing the load on other airports, noice pollution, and the infeasibility of enlarging Amsterdam's airport.

Attitude was measured according to Fishbein's method (Ajzen \& Fishbein, 1980; Fishbein \& Ajzen, 1975). A number of statements were offered covering all the issues mentioned above and the subject was asked whether these statements agreed with the subject's own opinion.

\section{Design and Subjects}

The study was carried out at party meetings; 268 Socialists and 295 Liberals took part, first watching one of the interviews on a video recorder and then completing a questionnaire. We employed a $2 \times 2 \times 2$ design with the following factors: attraction of the source (same party vs. opposing party), party membership of the subjects (Liberal-Socialist), and delivery (rational vs. 
emotional). The subjects were randomly assigned to the conditions. There were also two control groups, one for each party, in which the subjects did not see any television interview.

\section{Results}

\section{Checking Experimental Manipulations}

We first wanted to know whether a difference could be found between the evaluation of the source of the same party and that of the opposing party. Therefore, the subjects in the control condition were asked to rate the two politicians as regards sympathy on a 7-point Likert scale. It was found that the source from the same party was regarded as significantly more likable than the source from the opposing party $(F=334.16, d f=1 / 199, p<.001)$, so that we can consider the variation in what we call attraction as successful.

Another question was whether the subjects did in fact perceive the emotional delivery as more dynamic than the rational one. The subjects in the experimental conditions judged the politician in the rational version as significantly less dynamic ( 7 points, Likert scale) than the politician in the emotional one $(F=168.43, d f=1 / 338, p<.001)$. It was also established that the delivery influenced the credibility of the source $(F=5.71, d f=1 / 329, p<.05)$ : The politician who spoke emotionally had a lower credibility. Furthermore, the emotional politician was perceived as less convincing $(F=8.40, d f=1 / 338$, $p<.01)$ and his argumentation was considered weaker $(F=9.45, d f=1 / 338$, $p<.01$ ), while no significant differences were found in expertise and sympathy.

Our final question was whether the members of the Socialist party differed initially-in the control conditions-from the Liberal party members in attitude and hence discrepancy. The mean attitude scores of the subjects of both parties are reported in Table 1 . In the control conditions the attitude of the subjects on the different topics was rather neutral; none of the scores (9-point scale) was lower than 4 or higher than 7 .

It was found that in the control group the Socialist and the Liberal subjects differed in attitude on all seven attitude topics together (multivariate analysis of variance, $F=12.87, d f=7 / 193, p<.001$ ). Univariate testing indicated that there was a significant difference in attitude toward six of the seven topics. The differences found were not all in the same direction. In four cases the Liberals had a higher attitude score than the Socialists: on the establishment of a second national airport, the choice of the Markerwaard area, the pressure for a quick decision, and the increase in air traffic. On the other two issues-noise pollution and not enlarging Amsterdam's airport-the Socialists obtained a higher score. A high score means that the subject's attitudes concur with those of the source; the opposite is true of a low score. Also, a high attitude score implies low discrepancy with the source. 


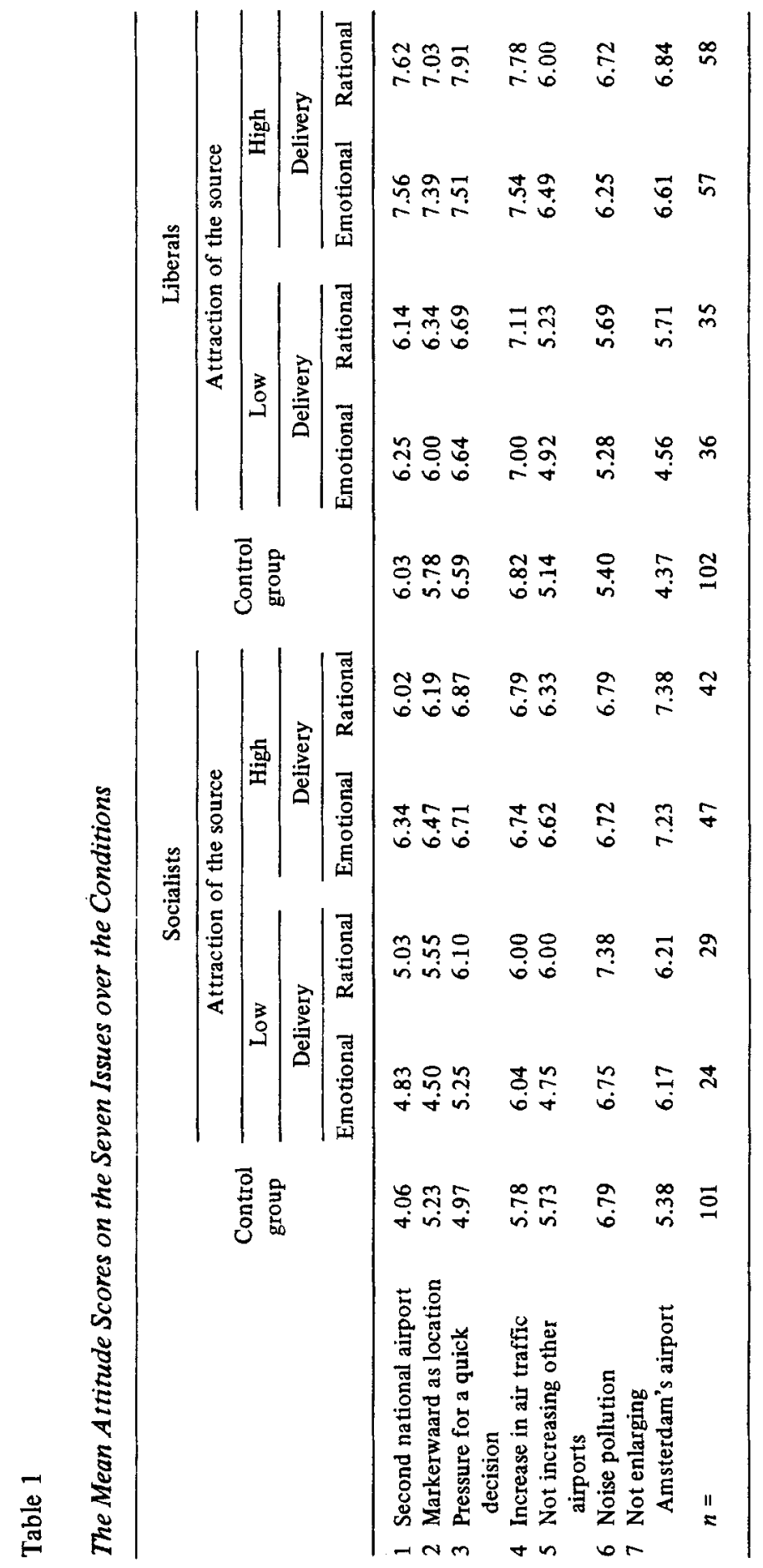




\section{Other Results}

To test the first hypothesis the results in the experimental conditions were compared with those in the control conditions (for mean attitude scores see Table 1). A significant difference in attitude was found between the control conditions and the experimental conditions on all seven topics together (multivariate analysis of variance: $F=17.78, d f=7 / 513, p<.001$ ). Univariate testing indicated significant differences for all seven topics separately (all $p<.01$ ). On the basis of the mean scores it was established that attitude change had taken place on all seven attitude topics in the direction of the content of the message. Thus our first hypothesis has been sustained: The experimental television interview had directly affected the attitude of the subjects.

To test the second hypothesis, multivariate analyses of variances were performed on the experimental conditions (see Table 2), taking as factors (1) the attraction to the source (source from the same party versus source from the opposing party), (2) party of the subject (Liberal versus Socialist), (3) intensity of delivery (emotional versus rational).

For attraction, a significant multivariate difference was found $(F=9.59$, $d f=7 / 134, p<.001)$. Univariate analyses of variance showed a significant difference for six of the seven attitude issues. The source from the same party was more able to convince subjects than the other source. Attitude change cannot actually be inferred from these data and should be assessed by comparing the experimental with the control conditions. This means we must establish whether a more attractive source elicits more attitude change than a less attractive source; that is, the difference between the differences must be tested for statistical significance. For this purpose Helmert contrast analyses were used. A multivariate Helmert contrast test for the factor attraction indicated a significant difference between the experimental and the control conditions $(F=3.69, d f=7 / 513, p<.001)$. Univariate contrast testing showed a significant difference on three attitude issues, namely the establishment of a second national airport, not enlarging Amsterdam's airport, and the pressure for a quick decision. On these three issues significantly more attitude change was elicited by the attractive source than by the unattractive one. The differences on the remaining four issues were statistically not significant, although they were in the expected direction. Thus, our second hypothesis has mainly been sustained.

As can be seen from Table 2, we also found a significant difference on the factor party of the subject (multivariate: $F=11.11, d f=7 / 314, p<.001$ ) and univariate analysis of variance showed that the Socialists differed from the Liberals on all six attitude topics for which a significant difference was also found in the control groups (see Table 1). To test the difference in attitude change between the experimental and the control conditions, Helmert contrast tests were again used. A multivariate Helmert contrast test for the 
Table 2

Multivariate and Univariate Analysis of Variance on the Scores of the Seven Attitude Topics (factors: attraction of the source, party membership, intensity of delivery).

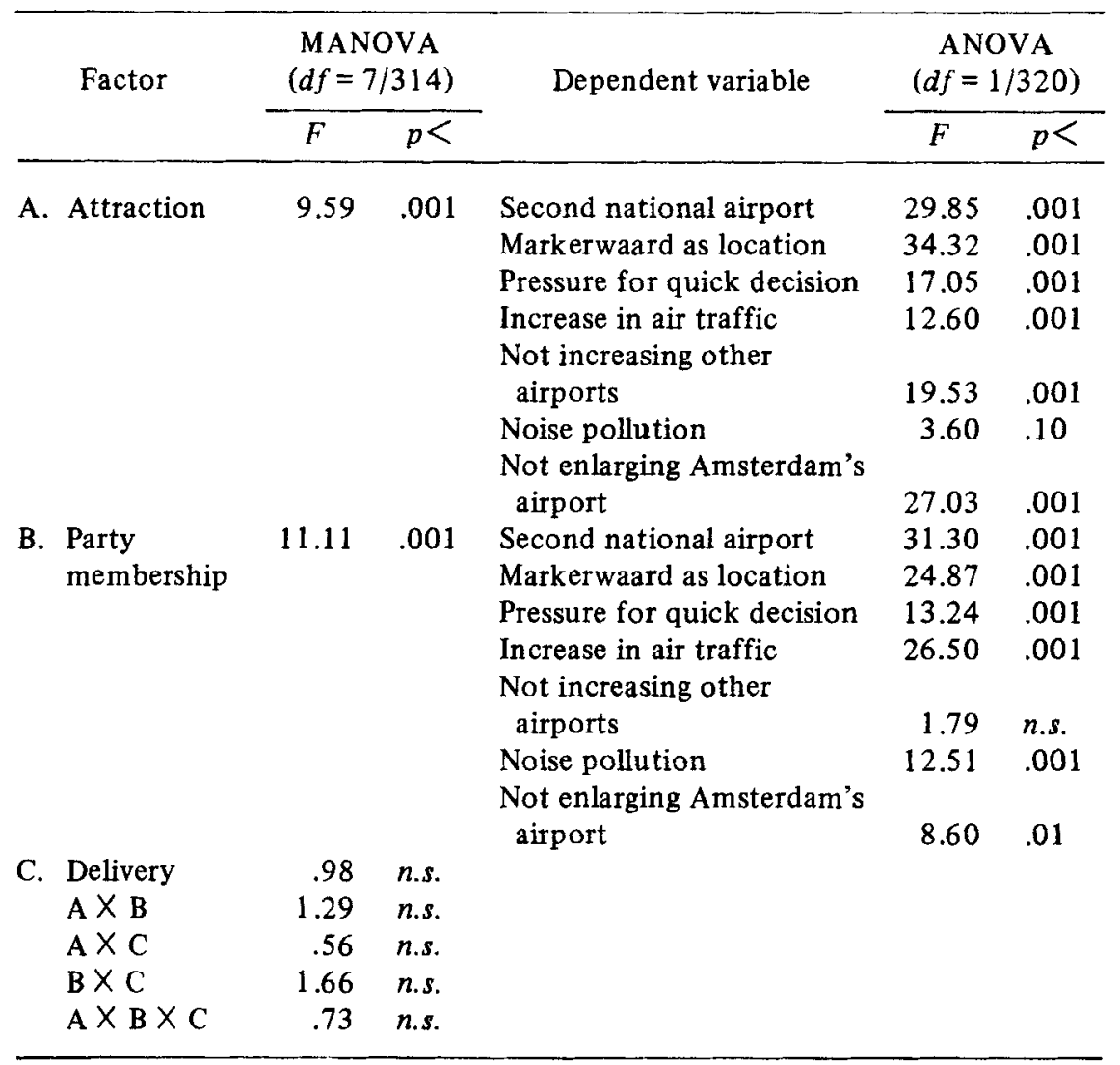

factor party indicated a significant difference between the relevant control and experimental conditions $(F=3.02, d f=7 / 513, p<.01)$. The univariate contrast test showed significant differences for three attitude topics. The Socialists changed their opinion more than the Liberals on the establishment of a second national airport $(F=6.94, d f=1 / 519, p<.01)$ and on the pressure for a quick decision $(F=5.00, d f=1 / 519, p<.01)$, whereas the Liberals were influenced more by the topic of noise pollution $(F=5.64, d f=1 / 519$, $p<.01$ ). On the first two issues, the Socialists in the control groups showed 
highest discrepancy, while on the last issue the Liberals were more discrepant (see Table 1). On the remaining four issues, no significant differences in attitude change were found, but this was not surprising considering that there was the least discrepancy on these issues in the control groups (all $F$ values were lower). Thus, our expectation that greater attitude change would take place at a high level of discrepancy than at a low level of discrepancy has mainly been sustained for both groups of subjects.

For the factor intensity of delivery no significant effect was found (multivariate: $F=.98, d f=7 / 314, n . s$.). Despite the lower credibility of the emotional source, the method of presentation evidently had no effect on attitude change. As can be seen from Table 2, none of the interaction effects reached statistical significance.

\section{Discussion}

A remarkable finding was that both experimental television interviews with Van Thijn and Wiegel led, in themselves, to attitude change. On all seven issues opinions had changed due to the program. We take this result as supporting our proposition that the mass media-in this case television-can indeed have a direct effect on public attitudes, assuming that certain conditions are fulfilled.

The variation in what we call the attraction of the source, as realized by presenting a politician to subjects of the same or the opposing party, has mainly had the predicted effect on attitude change. On three of the seven issues, attitude change after seeing the interview with the attractive source was significantly greater than after seeing the less attractive politician, while on the four remaining issues there was an effect in the expected direction. Our second hypothesis has thus mainly been substantiated.

We chose sympathy for the source as the dependent measure of attraction. We were guided here, by evidence in the relevant literature, that sympathy is closely related to the variations in attraction in our experiment, namely the similarity in group membership and attitudes between source and subjects. A significant difference was found between the two sources, both for the Socialist and the Liberal subjects. The subjects rated the politician from their own party as more likable than the politician from the opposing party. There was an initial difference between the Socialists and Liberal subjects in discrepancy on six of the seven attitude topics.

From a comparison of the control and the experimental conditions, it became evident that there had been significantly more attitude change on exactly the same three topics in which the discrepancy initially was greatest. Thus our expectation as far as discrepancy concerned has been mainly supported. This result cannot be attributed to the members of either political party. There 
was no direct relation between discrepancy and party membership; on some issues the Socialists in the control groups were more discrepant than the Liberals, while on other issues the opposite was true. Our conclusion is therefore that the frequently reported finding has been confirmed, namely that with higher but not extreme discrepancy, more attitude change occurs than with lower discrepancy. It should be borne in mind that in the case of lower discrepancy there is simply less room for attitude change (Insko, 1967; Insko \& Schopler, 1972).

In the relevant literature an interaction effect is frequently reported between the discrepancy and the credibility of the source (cf. Aronson, Turner, \& Carlsmith, 1963; Bochner \& Insko, 1966; Halperin, Snyder, Shenkel, \& Houston, 1976; McGinnies, 1973). With high discrepancy a highly credible source is assumed to have more effect than a less credible source, but for a source with low discrepancy credibility scarcely plays a part. If we assume that the attraction of the source is related to discrepancy in the same way as credibility, we could state that in the case of high discrepancy the source from the same party would elicit more attitude change than the source from the opposing party but in the case of low discrepancy both sources would have about the same effect. However, we did not find a significant interaction effect between attraction and party membership of the subjects being the factor in which a substantial variation in discrepancy was found. An explanation for this finding could be that the leading politicians who cooperated in our research already had an established attraction and credibility. It is therefore probable that the influence of a powerful source does not depend on discrepancy. This would imply that even in the case of low discrepancy the source from the same party would still have more effect than the source from the opposing party. Moreover, this is in line with common sense: nobody would expect a Socialist to be influenced just as strongly by a Liberal front-rank speaker as by a senior spokesperson from the Socialist's own party, even when there is low discrepancy. We assume that our finding could lead to a reevaluation of current opinions on the effect of the source. Further research is required here, using well-known people as sources, as it is they who in reality have the most influence on opinions in our society.

The variation in intensity of delivery-emotional versus rational-had no influence on attitude change, although we had established that delivery did have an effect on the credibility of the source. An emotional source was judged less credible. We also discovered that the emotional source was less convincing and weaker in his arguments than the rational source. The expertise and sympathy of the source were not affected by delivery. From this we must conclude that the objectivity aspect of credibility is influenced by the intensity of delivery. This last result accords completely with the findings of other researchers (e.g., Pearce \& Brommel, 1972; Pearce \& Conklin, 1971; Vincenzo \& Hendrick, 1974). 
Although the intensity of delivery by the source seems to be an important variable in the context of propaganda, in our study no effect was found on attitude change. As most research on this topic presents a far from simple picture, this should not be taken as an unusual result. We should add here that we tried to keep the variation in delivery as realistic as possible so that it would not seem over done. Wiegel and Van Thijn did not adopt an exaggerated tone when performing in the emotional condition; nor did they exhibit hysterical or absurd behavior. The possibility that a more extreme variation in delivery would have had an influential effect on attitude change should not be ruled out. However, there is a great risk that a more extreme artificial variation would induce suspicion in the subjects.

\section{References}

Ajzen, I., \& Fishbein, M. (1980). Understanding attitudes and predicting social behavior. Englewood Cliffs, NJ: Prentice-Hall.

Aronson, E., \& Golden, B. (1962). The effect of relevant and irrelevant aspects of communicator credibility on opinion change. Joumal of Personality, 30 , 135-146.

Aronson, E., Turner, J. A., \& Carlsmith, J. M. (1963). Communicator credibility and communication discrepancy as determinants of opinion change. Journal of Abnormal and Social Psychology, 67, 31-36.

Ban, A. W. van den. (1964). A revision of the two-step flow of communication hypothesis. Gazette, 10, 235-250.

Bochner, S., \& Insko, C. A. (1966). Communicator discrepancy, source credibility and opinion change. Journal of Personality and Social Psychology, 4, 614-621.

Bowers, J. W. (1965). The influence of delivery on attitudes towards concepts and speakers. Speech Monographs, 32, 154-158.

Brock, T. C. (1967). Communication discrepancy and intent to persuade as determinants of counterargument production. Journal of Experimental Social Psychology, 3, 296-309.

Coats, W. D., \& Schmidchens, U. (1966). Audience recall as a function of speaker dynamism. Journal of Educational Psychology, 57, 189-191.

Comstock, G. (1975). The evidence so far: The effect of television on children and adolescents. Joumal of Communication, 25, 25-34.

Comstock, G. (1978). The impact of television on American institutions. Joumal of Communication, 28, 12-28.

Dietrich, J. E. (1946). The relative effectiveness of two modes of radio delivery in influencing atttidues. Speech Monographs, 13, 58-65.

Fishbein, M., \& Azjen, I. (1975). Belief, attitude, intention and behavior: An introduction to theory and research. Reading, MA: Addison-Wesley. 
Foley, J. M. (1978). Mass Communication theory and research: An overview. In B. Ruben (Ed.), Communication Yearbook 2 (pp. 209-214). New Brunswick, NJ: Transaction Books.

Foley, J. M. (1979). Mass Communication theory and research: An overview. In D. Nimmo (Ed.), Communication Yearbook 3 (pp. 263-270). New Brunswick, NJ: Transaction Books.

Granberg, D., \& Campbell, K. E. (1977). Effect of communication discrepancy and ambiguity on placement and opinion shift. European Journal of Social Psychology, 7, 137-150.

Halperin, K., Snyder, C. R., Shenkel, R. J., Houston, B. K. (1976). Effects of source status and message favorability on acceptance of personality feedback. Journal of Applied Psychology, 61, 85-88.

Himmelfarb, S., \& Arazi, D. (1974). Choice and source at tractiveness in exposure to discrepant messages. Journal of Experimental Social Psychology, 10, 516-527.

Hovland, C. I., Janis, I. L., \& Kelley, H. H. (1953). Communication and persuasion. New Haven, CT: Yale University Press.

Hovland, C. I., Lumsdaine, A. A., \& Sheffield, F. D. (1949). Experiments on mass communication. Princeton University Press.

Insko, C. A. (1967). Theories of attitude change. New York: Appleton-CenturyCrofts.

Insko, C. A., \& Schopler, J. (1972). Experimental social psychology. New York: Academic Press.

Jones, R. A., \& Brehm, J. W. (1967). Attitudinal effects of communicator attractiveness when one chooses to listen. Journal of Personality and Social Psychology, 6, 64-70.

Liebert, R. M., \& Schwartzberg, N. S. (1977). Effects of mass media. Annual Review of Psychology, 28, 141-173.

McGinnies, E. (1973). Initial attitude, source credibility and involvement as factors in persuasion. Journal of Experimental Social Psychology, 9, 285-296.

McGuire, W. J. (1964). Inducing resistance to persuasion: Some contemporary approaches. In L. Berkowitz (Ed.), Advances in experimental social psychology (Vol. 1, pp. 191-229). New York: Academic Press.

McGuire, W. J. (1969). The nature of attitudes and attitude change. In G. Lindzey \& E. Aronson (Eds.), The handbook of social psychology (2nd ed., Vol. 3, pp. 136-314). Reading, MA: Addison-Wesley.

Nemeth, C., \& Endicott, J. (1976). The midpoint as an anchor: Another look at discrepancy of position and attitude change. Sociometry, 39, 11-18.

Pearce, W. B., \& Brommel, B. J. (1972). Vocalic communication in persuasion. Quarterly Journal of Speech, 58, 298-306.

Pearce, W. B., \& Conklin, F. (1971). Nonverbal vocalic communication and perceptions of a speaker. Speech Monographs, 38, 235-241. 
Sherif, C. W., Sherif, M., \& Nebergall, R. E. (1965). Attitude and attitude change: The social judgment-involvement approach. Philadelphia: Saunders.

Vincenzo, J., \& Hendrick, C. (1974). Impact of sound effects and dramatic speech style on speaker perception, attitudes and speech recall. Bulletin of the Psychonomic Society, 3, 434-436.

Watt, J. H., \& Berg, S. A. van den. (1978). Time series analysis of alternative media effects theories. In B. D. Ruben (Ed.), Communication Yearbook 2 (pp. 215-224). New Brunswick, NJ: Transaction Books.

Watts, W. A., \& Holt, L. E. (1979). Persistence of opinion change induced under conditions of forwarding and distraction. Joumal of Personality and Social Psychology, 37, 778-789.

White, G. M. (1975). Contextual determinants of opinion judgments: Field experimental probes of judgmental relativity boundary conditions. Journal of Personality and Social Psychology, 32, 1047-1054.

Wiegman, O., Roon, A. D. de, Snijders, T. (1981). Meningen en Media, Deventer, Netherlands: Van Loghum Slaterus.

Wiegman, O., Baarda, B., Seydel, E. R. (1983). Holland: Research on the causes and prevention of aggression. In A. P. Goldstein \& M. H. Segall (Eds.), Aggression in global perspective (pp. 198-221). New York: Pergamon Press.

Zucker, H. G. (1978). The variable nature of news media influence. In B. D. Ruben (Ed.), Communication Yearbook 2 (pp. 225-240). New Brunswick, NJ: Transaction Books. 